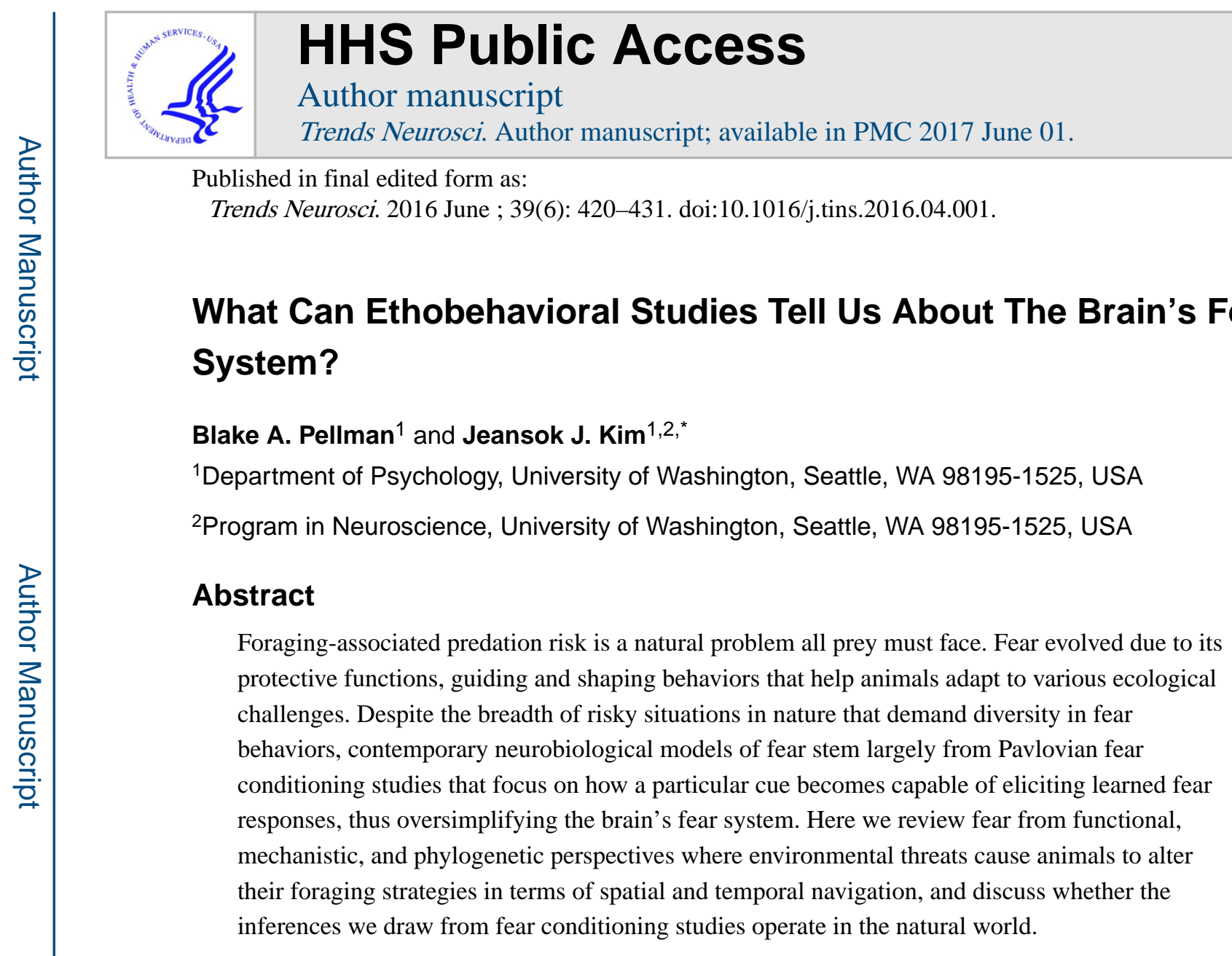

\title{
Keywords
}

amygdala; hippocampus; decision-making; foraging; place cells; circadian rhythms

\section{The Nature of Fear}

Fear is a defensive mechanism that rapidly activates coordinated bodily and behavioral responses to environmental stimuli that the brain, as a result of genetics and experience, has come to recognize as potentially dangerous. The fear system likely evolved because animals that successfully evade predatory threats while foraging for resources (e.g., food, water, mate, shelter) have a reproductive advantage over those that do not [1]. The brain's ability to instinctively recognize and respond accordingly to certain dangers and undergo experiencedependent plasticity to new threats is thus predicated by the evolutionary pressure (see Glossary) associated with each species' interactions within its ecological niche (Figure 1). For example, the main defensive behavior displayed by the woodland-living deermouse, Peromyscus maniculatus austerus, is freezing, which provides a stealth function against its

\footnotetext{
*Correspondence: ; Email: jeansokk@u.washington.edu (J.J. Kim)

The authors declare no competing financial interests.

Publisher's Disclaimer: This is a PDF file of an unedited manuscript that has been accepted for publication. As a service to our customers we are providing this early version of the manuscript. The manuscript will undergo copyediting, typesetting, and review of the resulting proof before it is published in its final citable form. Please note that during the production process errors may be discovered which could affect the content, and all legal disclaimers that apply to the journal pertain.
} 
natural predators (e.g., the weasel's sensitivity to the prey's movement), whereas the vertical leap response of the arid region-residing deermouse, Peromyscus maniculatus gambeli, is adaptive against its natural predators (e.g., the gopher snake's strike) [2]. Likewise, each species' biological history predisposes fear learning to certain stimuli and not others. A canonical example of this is the discovery that laboratory rats can easily learn, via Pavlovian conditioning, to associate sound/light with footshock (fear conditioning) and tastes with emetic agents (conditioned taste aversion) but cannot associate sound/light with emetics and tastes with footshock [3]. Presumably, rats have an evolutionary history of encountering the temporal coincidence of sound/visual (but not taste) cues with cutaneous pain of predatory attack and experiencing the delayed temporal overlap of taste (but not sound/visual) cues with gustatory pain of consuming poisonous food. In contrast, birds rely on visual acuity for searching for food and thus easily associate visual cues with emetic food [4], such as the monarch butterfly's wing pattern and its cardenolides poison. Thus, the rodent brain's capacities to rapidly and lastingly associate auditory and ocular inputs with cutaneous paininducing stimuli (including artificial footshock) and taste inputs with gustatory illnessinducing stimuli have evolved as a genetic trait. Consistent with this notion, a recent study found that different populations of neurons dispersed in the basolateral nucleus of the amygdala (BLA) become activated to either context-footshock or saccharin-LiCl conditioning, but not to both [5], providing evidence of biologically predisposed learning at the cellular level within the same brain region. Similarly, a subset of distributed neurons in the dorsal pedal ganglion of the marine mollusk Tritonia are predetermined to develop into memory networks [6]. Such distinct neuronal information processing likely enables the same brain structures to perform diverse functions effectively.

In this review, we will examine the current status and future directions of fear research from an eco-evolutionary perspective in which animals' innate and acquired fear responses have been shaped by its ecological niche. First, we will briefly summarize recent findings from Pavlovian fear conditioning studies, the neurobiological picture of fear they have provided, and outline some major questions these studies have created. We will then discuss ethological approaches to studying fear and how they may provide a more comprehensive and naturalistic understanding of fear dynamics and its circuity.

\section{Contemporary Models of Fear Conditioning}

Current neurobiological models of fear have progressed from nearly a century of Pavlovian fear conditioning research in animals and humans (Figure 2). It is generally agreed in the field that information about the conditioned stimulus (CS; such as tones or lights for discrete 'cued' conditioning; experimental chambers for 'contextual' conditioning) and unconditioned stimulus (US; such as electric shocks, loud sounds) converge in the amygdala, where associative (Hebbian) synaptic plasticity (e.g., long-term potentiation, LTP) strengthens the CS afferents to amygdalar neurons, enabling the CS to autonomously produce conditioned fear responses (CR) [7-9]. Evidence further suggests that fear conditioning to different CS information occurs in distinct amygdalar nuclei, i.e., the lateral/ basolateral nucleus (LA/BLA) for tone CSs via the auditory thalamus and cortex; the basolateral complex for light CSs via the visual thalamus; and the basal nucleus (BA) for contextual CSs via the hippocampus $[8,10]$. These CS-US association nuclei are 
interconnected with the central nucleus (CEA), which projects to downstream structures that mediate specific fear responses, e.g., the periaqueductal gray (PAG) and freezing. Additionally, infralimbic (IL) and prelimbic (PL) regions of the medial prefrontal cortex (mPFC) have been proposed to exert 'top-down' control of the amygdala [11]; e.g., the ILITC (intercalated cells of the amygdala) pathway for the extinction (or inhibition) of conditioned fear, and the PL-LA pathway for the expression of CRs [12]. The hippocampus is also implicated when spatial/contextual information influences fear conditioning [13, 14], and a very recent study revealed that a monosynaptic projection from the anterior cingulate to the hippocampus mediates retrieval of contextual fear memory [15]. Thus, different afferents to and efferent targets from the amygdala seem to be hardwired for fear conditioning to specific CS information and to generate different CRs [16]. [We refer the reader to the following articles for a more focused discussion on neural mechanisms and different types of fear conditioning (e.g., to social or olfactory cues): [17-22].] While recent optogenetics and genetic ablation studies have generated new information about inter- and intra-amygdala circuits and cellular-molecular mechanisms of fear, there are still unresolved core issues and some new findings requiring reappraisal.

\section{What is the essential US pathway?}

Compared to CS information pathways to the amygdala (particularly auditory information), much less is known about how US information reaches the amygdala. Because fear conditioning is only one of several operations of the amygdala [23-26], those neurons that are essential to the formation of a conditioned fear memory should be distinct from other, non-fear-functioning neurons by receiving (or being capable of rewiring to receive) both CS and US afferents in order to undergo associative synaptic plasticity. The PAG and the parabrachial nucleus (PBN), two components of the ascending pain transmission pathway [27], are postulated as providing footshock-US inputs to the amygdala. Electrical stimulation of the dorsal PAG, which produces strong activity bursts (jumping and running), have been shown to be a sufficient surrogate US to support auditory and contextual fear conditioning in rats [28]. Correspondingly, pharmacological inactivation of PAG neurons attenuated periorbital shock US-evoked response in LA neurons and decreased acquisition of auditory fear conditioning [29] (but see [30]). This study [29] further showed that PAG neurons are initially responsive to the US, but as the conditioned fear developed, the US-evoked responses in the PAG decreased via the increasing amygdala-PAG pathway-mediated analgesia. In essence, this negative feedback characteristic of the amygdala-PAG circuit represents a biological analog of the Rescorla-Wagner model [31] of Pavlovian fear conditioning [18]. Another recent study showed that optogenetic silencing of the calcitonin gene-related peptide (CGRP)-expressing neurons in the PBN, or their terminals in the CEA, blocked the footshock-US's ability to support contextual and auditory fear conditioning [32]. Conversely, optogenetic stimulation of these originating and terminal regions served as an effective US in fear conditioning. Given the monosynaptic dPAG-PBN projection [33], it appears that the dPAG and PBN constitute an overlapping US pathway to the amygdala, and the finding that silencing PBN neurons blocked fear conditioning to a footshock-US suggests that the PAG's indirect pathways to the BLA and reciprocal connections with the CEA are not necessary for fear conditioning to footshock-US. If the dPAG and PBN are indeed both sufficient and necessary in relaying the footshock-US information to the 
amygdala, a straightforward prediction would be that, in previously fear conditioned animals, subsequent silencing/lesioning of neurons in these structures with continued CS-US presentations should lead to a gradual extinction because the amygdalar neurons would only be receiving unreinforced CS information. This "litmus test" de rigueur for confirming the essential US pathway [34] has yet to be performed. Future studies will also need to investigate non-pain US pathways to the amygdala that support fear conditioning, such as loud noise [35] and predatory odor [36]. Most likely, a network of amygdalar neurons that represents a conditioned fear memory must receive both CS and US inputs, and thus characterizing the projection topography of different USs on amygdalar nuclei has significance to optogenetic, genetic ablation and cellular imaging studies.

\section{What is the role of the CEA in fear learning?}

Although most fear conditioning models portray the CEA as the CR output structure of the amygdala, evidence is emerging that the CEA is also involved in CS-US association formation [37]. For example, functional and genetic circuit analyses have shown that the lateral subdivision of the CEA (CEl) is involved in the acquisition of auditory fear conditioning whereas the medial subdivision of the CEA (CEm) mediates the expression of fear CRs $[38,39]$. Specifically, fear conditioning seems to require glutamatergic plasticity in a subpopulation of CEI inhibitory neurons (signified as " $\mathrm{CEI}_{\text {on }}$ ") that inhibit a different subpopulation of $\mathrm{CEI}$ inhibitory neurons (" $\mathrm{CEI}_{\text {off }}$ "). $\mathrm{CEI}_{\text {off }}$ neurons normally inhibit $\mathrm{CEm}$ neurons, but CS-evoked activation of the $\mathrm{CEI}_{\text {on }}$ neurons suppresses $\mathrm{CEI}_{\text {off }}$ neurons, leading to increased CEm activity and the expression of fear CRs. Consistent with the CEA's role in fear learning, the terminals of CGRP neurons in the PBN that relay footshock-US information were selectively found in the $\mathrm{CEl}$ but not the BLA [32]. A perplexing question that needs to be addressed is how inhibition/suppression of either the BLA or CEA (or even PL [40] or cerebellum [41]) alone effectively blocks auditory fear conditioning when other regions' functions are presumably intact (see Box 1). If fear conditioning engages distributed parallel brain networks, then inhibiting the CEA during fear conditioning should not affect other brain regions receiving CS and US inputs from undergoing learning-induced plasticity. Once the CEA is back to normal, the animal should be able to express learned fear responses. The fact that this is not the case suggests that fear conditioning requires presently unknown interactions - perhaps functional connectivity-between multiple fear networks such that inhibition of one disrupts the others.

\section{Box 1}

\section{Fear without the amygdala}

While many fear responses require the amygdala in order to be expressed, some studies suggest other circuitry can mediate fear responses in the absence of the amygdala. For example, patients with bilateral amygdala lesions due to Urbach-Wiethe disease do not exhibit fear responses to a variety of normally fear-eliciting stimuli and are unable to acquire fear through conditioning [87]. However, inhalation of $\mathrm{CO}_{2}$ is still capable of eliciting panic-like responses in these patients. The circuits mediating such responses in the absence of the amygdala remain uncertain, but potential candidates have been identified. The PAG may be part of the circuit, as previous research has shown that 
stimulation the PAG in humans induces sensations of panic [88], but hypothalamic regions may be sufficient for fear responses and learning as well [89].

\section{How do amygdalar neurons support diverse behavioral functions?}

Given that the amygdala (including LA) is also implicated in appetitive/reward learning, attention, memory modulation, aggression, sex, decision-making, and social behavior [2326], it is vital to understand how its neurons participate in fear conditioning while integrating other behavioral functions. As mentioned in the opening, one possibility is that there are different subsets of amygdalar neurons that are prewired to different functions, consistent with the notion of biologically predisposed learning (Figure 1) [3, 5, 6]. The other possibility is that amygdalar neurons (or a subset of neurons) have pleiotropic mnemonic functions and that those with relatively elevated intracellular protein signals related to neuronal plasticity become preferentially engaged during any amygdala-dependent experience (Figure 3). Consistent with the latter view are findings that the cyclic adenosine monophosphate-responsive element binding protein (CREB) is crucial for the formation of contextual fear memories [42], that LA neurons with relatively higher CREB activity are preferentially recruited into an auditory fear memory [43], and that post-training selective ablations, via an inducible diphtheria toxin (DT), of $\sim 15 \%$ sparsely-distributed LA neurons overexpressing CREB, 'tagged' via replication-defective herpes simplex viral (HSV) vectors, permanently abolished auditory fear memory [44, 45]. Following the DT-induced loss of memory retrieval, the animals were able to relearn the conditioned fear response, suggesting that amongst the remaining neurons, those with relatively higher CREB activity were successors to encoding this auditory fear memory. However, whether these CREBoverexpressing neurons receive both CS and US inputs, a crucial requirement for encoding fear memory, has not been confirmed. Recent cellular compartment analysis of temporal activity by fluorescence in situ hybridization (catFISH) studies reported that only about $4 \%$ of neurons in the LA/BLA showed coincident ArC/Arg3.1 (an immediate early gene expressed in glutamatergic neurons) mRNA activation to both CS and US events [5, 46]. If a small fraction of dispersed LA neurons receive convergent CS and US inputs, and it is unlikely that the HSV vectors would selectively target those neurons in advance of fear conditioning, then the post-training induced ablation likely included nonspecific cell death that indirectly affected fear CRs rather than excised the fear engram per se. Similarly, opto/ chemo-genetic activation studies of fear conditioning do not demonstrate that all virallyinfected neurons with the same promotor are fear-functioning neurons. In the authors' view, it is more likely that broad stimulation of the amygdala triggers fear behaviors because these output circuits would have the lowest thresholds for activation if the brain is wired to err on the side of survival. Future studies will need to address whether fear memories are encoded in the amygdala via biologically predisposed neurons or via pleiotropic-functioning neurons based on their relative CREB activity. One possible avenue of research is to stimulate the US pathways (dPAG and PBN) to overexpress CREB selectively in US-responsive amygdalar neurons, and quantify and ablate those neurons pre hoc to see if fear conditioning can be permanently prevented [28]. 


\section{Ethological Approaches to Studying Fear}

Despite the advances made, fear conditioning research likely provides an incomplete picture of the brain's fear system because it is based on assessing the magnitude of a specific response (e.g., freezing) in a small experimental chamber that restricts the animal's repertoire of behavior (see Box 2). In nature, foraging distance and duration correlate with the likelihood of encountering predatory (and other) threats (Figure 4), and fear serves two general functions - an immediate defensive response when facing predators and an enduring influence on foraging strategy as a function of experience [47-49]. Ethologically-relevant paradigms provide a greater match to the real-world threat situations that the brain's fear system evolved to solve, and thus present means to critically evaluate the utility of fear conditioning models. Whereas fear conditioning research typically emphasizes the processes underlying fear learning specifically, ethological studies can provide greater control over the degree to which innate and learned fear interact, allowing researchers to study the functional relationships between innate and learned fear in situations that simulate contingencies animals are likely to encounter in the wild. Several studies have employed such paradigms to study fear in rodents, and demonstrate the significance of innate fear in evading predation.

\section{Box 2}

\section{Fear conditioning in nature?}

"No real-life predator is going to present cues before it attacks... [or give] enough trials for the necessary learning to occur... What keeps [foraging] animals alive in the wild is that they have very effective innate defensive reactions which occur when they encounter any kind of new or sudden stimulus". Robert Bolles (1970)

While learning about threats in the environment is an important function for survival, the generalizability of fear conditioning studies has been called into question [90]. The primary issue is that instinctive fear to sudden stimuli (auditory, visual, olfactory, etc.) would provide a competitive advantage over the time-consuming and hazardous process of trial-and-error learning. In the case of predator-prey interactions, there is a constant arms-race: Predators will benefit by minimizing their detectability/predictability and prey will benefit by increasing their sensitivity, and consequently their false alarm rate.

\section{Innate danger signals}

Many species instinctively respond to simple yet reliable indicators of threat. For example, "looming stimuli", simple cues that expand rapidly in the visual field, mimicking advancing predators, elicit avoidance responses in diverse species [50]. Recently, Yilmaz and Meister [51] showed that overhead visual display of a rapidly expanding dark disc, akin to a shadow cast by an approaching aerial predator, triggers immediate flight and freezing behavior in mice. Münch and colleagues [52] found that a subset of "OFF" retinal ganglion cells in mice respond selectively to stimuli approaching or increasing in size compared to laterallymoving or shrinking stimuli, perhaps allowing rapid responding to imminent threats without the need for cortical processing. Indeed, it has been shown that several types of motionsensitive retinal ganglion cells directly innervate the superior colliculus [53], and that 
neurons in the medial intermediate layers of the superior colliculus, which project to the BLA via the lateral posterior thalamus, are necessary for the defensive responses to looming stimuli [54].

Other studies [55-58] have utilized predator-like robots to examine naturalistic fear behavior within laboratory settings. For example, Choi and Kim [55] placed rats in a naturalistic 'approach food-avoid predator' situation to study how rats integrate appetitive and defensive motivations and make risky foraging decisions, and found that rats form a distance gradient of fear near the source of threat (Figure 5A). Furthermore, the amygdala was necessary for responding defensively to the robot [55], and amygdalar stimulation was sufficient to elicit the same defensive behavior in foraging rats sans external threat [28]. Interestingly, dPAG stimulation produced stronger defensive behavior than amygdalar stimulation, and the effect of dPAG stimulation was abolished by lesioning/suppressing the amygdala while the amygdalar stimulation effect remained intact with PAG lesions, suggesting that, in contrast to fear conditioning-based models (Figure 2), the amygdala may act downstream of the dPAG in responding to predators [28]. Very recently, Pare and colleagues [57] have used the same paradigm to characterize amygdala neuronal activity during risky foraging. When all projection neurons recorded in the BLA were analyzed, about $69 \%$ decreased while $7 \%$ increased their firing rate when rats began foraging regardless of whether the robot or the food were present. These findings suggest that rather than signaling the presence of threat and activating defensive behavior, as concluded from amygdala recordings in Pavlovian fear conditioning studies [59], BLA activity is closely associated with actual behavioral output regardless of threat risk [57]. However, given previous research that shows BLA stimulation can produce multiple forms of defensive behaviors (i.e., freezing and escape) [28] and that distinct threats activate distinct amygdalar neurons [46], more research will be needed to differentiate whether the BLA gates locomotor behavior as opposed to playing a motivational role. A similar artificial predator approach has been used effectively in a different animal model system to demonstrate that a biomimetic robotic predatory fish elicits robust and consistent defensive behaviors in zebrafish (Danio rerio) [58]. The precise control achieved by using robotic threats provides an opportunity to understand the parameters of defensive behaviors and provide insight into the naturalistic workings of neural circuits.

There are likely many other stimuli that evoke innate defensive responses, such as olfactory and auditory cues associated with predators (see Box 3). Recent work by Zanette and colleagues $[60,61]$ used playbacks of predator vocalizations to effectively manipulate fear in songbirds (Melospiza melodia) and wild raccoons (Procyon lotor), demonstrating that innate fear alone has significant effects not only on the natural foraging decisions of diverse animals, but that these effects consequently affect the structure of the ecosystem. Thus, utilizing ethological approaches in both laboratory and field settings to understand the neural circuitry underlying innate fear signals and their roles in risky foraging decisions will undoubtedly prove fruitful. 


\section{Box 3}

\section{Predator odors and innate fear}

Olfactory cues associated with predators, such as cat fur/saliva [91], bobcat, weasel, ferret, and fox urine/feces $[92,93]$, have also been reported to evoke innate defensive responses in mice and rats, including avoidance, freezing, and stretch-attend posturing and other risk-assessment behaviors. Different predator odors seem to share some common features (e.g., sulfated chemical signatures) and substrates (e.g., olfactory receptors and the Grueneberg ganglion), and the lateral habenula and the dorsal tegmentum appear to be important for regulating fear responses to predator odors coordinated by hypothalamic nuclei [94]. Understanding these circuits and whether different predator odors activate different circuits will aid in the understanding of US pathways.

\section{Spatial dynamics of fear}

Ethological studies highlight how spatial factors influence 'cost-benefit' decisions while attaining resources and avoiding threats. While the hippocampus is well-known for encoding spatial information necessary for navigation [62, 63], initial fear studies examined its function in static fear conditioning contexts [64, 65]. Subsequent research has shown that, after fear conditioning, hippocampal place cells exhibit conditioned responses to the CS interval [66] and altered firing locations in fear-conditioned, but not control, chambers [67]. Remapping of place fields has also been observed following electrical stimulation of the amygdala in rats foraging for food on an open-field platform [68].

The precise behavioral functions of such changes are harder to understand, and will likely benefit from ethological approaches. For example, in rats placed in an 'approach food-avoid predator' situation, hippocampal place cells that had exhibited place fields located farthest from the 'safe' area before being exposed to the predatory robot remapped after encountering the robot (Figure 5B) [56]. In contrast, place fields inside and near the nest regions were unaffected by the predatory robot. These data suggest that place cells can delineate the boundaries of threat and safety as a function of distance. Similarly, a recent study [69] utilized an 'enemy avoidance' task in which rats foraged on a circular platform for food while attempting to avoid a moving robotic threat; if the rats were within $25 \mathrm{~cm}$ of the robot, they received a footshock. Inactivation of the dorsal hippocampus with tetrodotoxin significantly impaired avoidance of the moving robot. These studies support the notion that fear guides and shapes foraging behaviors in fluid risky foraging situations.

Ethological approaches are also successfully implemented to understand how humans perceive and process fear across spatial gradients. Mobbs and colleagues [70, 71] utilized functional magnetic resonance imaging (fMRI) and an "Active Escape Paradigm" (AEP) wherein a virtual predator chases a virtual representation of the participant, and upon being 'caught', the participants receive an electric shock. These studies showed that as the threat moves from a distal location toward imminent contact with the participant, neural activity shifts from the ventromedial PFC and amygdala toward the PAG. In another study [72], a 
live tarantula was moved closer to participant's feet while they were restrained in an fMRI machine, which produced similar patterns of neural activity to the AEP experiments and corresponds to similar findings of experiments in rodents [73]. Research on "defensive peripersonal space", an area in which defensive behaviors scale with distance from the body [74], in human and non-human primates [75, 76] suggests that parieto-frontal interactions also play a role in enhancing defensive reflexes as threats come closer to the body. Incorporating ethological stimuli and situations into human studies will provide a functional understanding of fear across spatial dimensions.

\section{Temporal dynamics of fear}

Predation risk and threat imminence also vary as a function of time, and thus fear is likely to influence decisions about the timing and duration of foraging activity. For example, Fenn and MacDonald [77] discovered a population of wild Norway rats (Rattus norvegicus), which are typically nocturnal, that exhibited diurnal rhythms of activity, presumably as a consequence of the presence of nocturnal red foxes (Vulpes vulpes) in the environment. A sample of the rats was brought into a safe enclosure, and they reverted to being nocturnal, suggesting that the diurnality effect was not due to direct predation but was instead an avoidance response to perceived risk. Laboratory research has shown that fear conditioning can disrupt entrainment of circadian rhythms in rodents [78], and clinical research demonstrates that fear- and anxiety-related disorders such as post-traumatic stress disorder are associated with disruptions to circadian rhythms in humans, including insomnia and irregular sleep patterns [79].

A recent study [80] directly tested whether nocturnal threat (unsignaled footshock) can shift the foraging time of rats living for extended periods in 'closed economy' chambers (Figure $5 \mathrm{~A}$ ), where fear and appetitive behaviors were an integrated part of the animals' lives. In response to nocturnal footshocks, animals switched their natural foraging behavior from the dark to the light phase, and maintained this switch under constant dark conditions. This suggests that rats were not conditioned to perceive the light cue as a safety signal to forage in a Pavlovian manner, but that the time-specific threat had influenced the rats' biological clocks. Lesioning either the suprachiasmatic nucleus ( $\mathrm{SCN}$ ), where the master circadian clock resides, as well as the amygdala, prevented the diurnality switch. These findings indicate that the amygdala and the SCN may interact as a fear-entrained oscillator that allows adaptation to cyclic predatory threats by predicting times of danger and temporally organizing foraging behavior accordingly (Figure 5C). Thus, time-varying threat influences behavior, and ethological studies examining temporal dynamics may provide important insights into the consequences of fear-related pathologies in people's day-to-day lives.

\section{Concluding Remarks}

While significant progress has been made through the use of fear conditioning paradigms, the evolutionarily conserved roles of fear in guiding and shaping foraging behavior have been overlooked in contemporary fear research. Fear conditioning studies in humans and animals focus on specific responses for brief periods of sampling, whereas ethological fear studies allow the tracking of relatively whole behavior in response to fear-evoking 
experiences. Furthermore, innate fear and its mechanisms are far less researched than acquired fear, but are at least equally important to survival. Both innate and learning systems interact at a fundamental level and the extent to which the neural processes underlying them are separable remains unclear. Ultimately, understanding their functional relationship will provide a more comprehensive understanding of the brain's fear system than trying to model them as distinct systems. State-of-the-art techniques for manipulating neurons and circuits provide neuroscientists with powerful means of understanding the brain, and coupling these with experimental methodology that captures naturalistic variability in behavior and the situations in which it is expressed will help researchers model the functional relationships between the organism and its environment. Future research should also examine individual differences within and across fear paradigms to better understand not only trait-level variability but also the correspondence (or lack thereof) between different measures of fear. Selective breeding for anxious [81] or depressive [82] traits are useful toward these ends, but understanding natural trait variability (e.g., $[72,83-86]$ ) will improve functional models of fear circuitry. These approaches will further help bridge the brain and behavioral sciences with ecological science to bring a unified understanding of the widespread biological functions of fear. Consequently, ethological studies of fear may lead to the development of useful ecosystem conservation strategies as well as more effective treatments for fear- and anxiety-related disorders, which are linked to alterations in behaviors tied to risk-assessment and decision-making - aspects that cannot be directly investigated in traditional fear conditioning studies.

\section{Acknowledgments}

This work was supported by NIH grant MH099073 (J.J. Kim).

\section{Glossary}

Circadian
rhythm

Evolutionary (or selective)

pressure

Genetic ablation

Hippocampal
place cells rhythmic patterns of activity restricted to specific times of the daily cycle, such as the daytime (diurnal), nighttime (nocturnal), or dawnand-dusk times (crepuscular), which are generated by endogenous molecular clocks with approximately 24 -h periods and "entrained" to external cues (zeitgebers), such as sunlight, to remain environmentally relevant

any environmental factors (e.g., predation) that decrease members of a species' reproductive fitness given their current physiological and behavioral traits

a method of using viruses to tag neurons that express a particular gene (e.g., induced by neural activation) and to selectively induce cell death in those neurons

neurons that fire burst spikes preferentially when the animal visits a specific location in a familiarized environment; collectively, these cells are hypothesized to provide a neural representation of the spatial environment 


\section{Immediate early gene}

Long-term potentiation

(LTP)

Optogenetics

\section{Pavlovian (or classical) conditioning}

RescorlaWagner model a gene that is expressed during or shortly following the onset of cellular activity (e.g., when a neuron fires an action potential)

a sustained enhancement of synaptic transmission following highfrequency stimulation of afferent fibers that has been demonstrated in several brain structures, such as the hippocampus and amygdala, and exhibits properties desirable for information storage (rapidly induced, strengthened by repetition, input specificity and associativity)

a method of precisely controlling the activity of neurons achieved by virus-driven expression of light-sensitive receptors that can be activated or deactivated by a laser focused through optic fibers implanted in the brain

the simplest form of associative learning where an initially neutral stimulus (conditioned stimulus, CS)—via contingent pairing with a biologically significant stimulus (unconditioned stimulus, US) that elicits an unlearned, reflexive behavior (unconditioned response, UR) - acquires a learned behavior (conditioned response, CR) that generally resembles the UR (but not always), precedes the US in time, and reaches a maximum at about the time of US onset

an influential learning algorithm, $\Delta \mathrm{V} n: \kappa(\lambda-\Sigma \mathrm{V} i)$, based on "US processing" that describes many conditioning phenomenon: $\kappa$ is a learning constant, $\lambda$ is the maximum associative strength obtainable with a given $\mathrm{US}, \Delta \mathrm{V} i$ is the sum associative strengths between all CS elements present and the US, and $\Delta \mathrm{V} n$ is the change in the associative strength of a particular CS on trial $n$

\section{References}

1. Darwin, C. The expression of the emotions in man and animals. J. Murray; 1872.

2. Hirsch SM, Bolles RC. On the ability of prey to recognize predators. Zeitschrift für Tierpsychologie. 1980; 54:71-84.

3. Garcia J, Koelling RA. Relation of cue to consequence in avoidance learning. Psychonomic science. 1966; 4:123-124.

4. Darwin, C. The origin of species by means of natural selection: or, the preservation of favoured races in the struggle for life and the descent of man and selection in relation to sex. Modern library; 1872.

5. Chung A, et al. Biologically predisposed learning and selective associations in amygdalar neurons. Learn Mem. 2011; 18:371-374. [PubMed: 21576517]

6 . Hill ES, et al. Memory formation in Tritonia via recruitment of variably committed neurons. Current Biology. 2015; 25:2879-2888. [PubMed: 26549261]

7. Johansen JP, et al. Hebbian and neuromodulatory mechanisms interact to trigger associative memory formation. Proc Natl Acad Sci. 2014; 111:E5584-E5592. [PubMed: 25489081]

8. Tovote P, et al. Neuronal circuits for fear and anxiety. Nat Rev Neurosci. 2015; 16:317-331. [PubMed: 25991441]

9. Orsini CA, Maren S. Neural and cellular mechanisms of fear and extinction memory formation. Neurosci Biobehav Rev. 2012; 36:1773-1802. [PubMed: 22230704] 
10. Duvarci S, Pare D. Amygdala microcircuits controlling learned fear. Neuron. 2014; 82:966-980. [PubMed: 24908482]

11. Gilmartin MR, et al. Prefrontal cortical regulation of fear learning. Trends Neurosci. 2014; 37:455464. [PubMed: 24929864]

12. Milad MR, Quirk GJ. Fear extinction as a model for translational neuroscience: ten years of progress. Annu Rev Psychol. 2012; 63:129-151. [PubMed: 22129456]

13. Orsini CA, et al. Hippocampal and prefrontal projections to the basal amygdala mediate contextual regulation of fear after extinction. J Neurosci. 2011; 31:17269-17277. [PubMed: 22114293]

14. Yoon T, et al. Hippocampal lesion effects on occasion setting by contextual and discrete stimuli. Neurobiol Learn Mem. 2011; 95:176-184. [PubMed: 20643219]

15. Rajasethupathy P, et al. Projections from neocortex mediate top-down control of memory retrieval. Nature. 2015; 526:653-659. [PubMed: 26436451]

16. Gross CT, Canteras NS. The many paths to fear. Nat Rev Neurosci. 2012; 13:651-658. [PubMed: 22850830]

17. Kim JJ, Jung MW. Neural circuits and mechanisms involved in Pavlovian fear conditioning: A critical review. Neurosci Biobehav Rev. 2006; 30:188-202. [PubMed: 16120461]

18. Fanselow MS, Wassum KM. The origins and organization of vertebrate Pavlovian conditioning. Cold Spring Harb Perspect Biol. 2016; 8:a021717. [PubMed: 26552417]

19. Mahan AL, Ressler KJ. Fear conditioning, synaptic plasticity and the amygdala: implications for posttraumatic stress disorder. Trends Neurosci. 2012; 35:24-35. [PubMed: 21798604]

20. Maren S. Neurobiology of Pavlovian fear conditioning. Annu Rev Neurosci. 2001; 24:897-931. [PubMed: 11520922]

21. Toth I, et al. Social fear conditioning: A novel and specific animal model to study social anxiety disorder. Neuropsychopharmacology. 2012; 37:1433-1443. [PubMed: 22237310]

22. Otto T, et al. Behavioral and neuropsychological foundations of olfactory fear conditioning. Behav Brain Res. 2000; 110:119-128. [PubMed: 10802309]

23. Everitt BJ, et al. Appetitive behavior. Ann N Y Acad Sci. 2003; 985:233-250. [PubMed: 12724162]

24. Moscarello JM, LeDoux JE. The contribution of the amygdala to aversive and appetitive Pavlovian processes. Emotion Review. 2013; 5:248-253.

25. Zeeb FD, Winstanley CA. Functional disconnection of the orbitofrontal cortex and basolateral amygdala impairs acquisition of a rat gambling task and disrupts animals' ability to alter decisionmaking behavior after reinforcer devaluation. J Neurosci. 2013; 33:6434-6443. [PubMed: 23575841]

26. Chang SWC, et al. Neural mechanisms of social decision-making in the primate amygdala. Proc Natl Acad Sci. 2015; 112:16012-16017. [PubMed: 26668400]

27. Almeida TF, et al. Afferent pain pathways: a neuroanatomical review. Brain Res. 2004; 1000:4056. [PubMed: 15053950]

28. Kim EJ, et al. Dorsal periaqueductal gray-amygdala pathway conveys both innate and learned fear responses in rats. Proc Natl Acad Sci USA. 2013; 110:14795-14800. [PubMed: 23959880]

29. Johansen JP, et al. Neural substrates for expectation-modulated fear learning in the amygdala and periaqueductal gray. Nat Neurosci. 2010; 13:979-986. [PubMed: 20601946]

30. Kim JJ, et al. Effects of amygdala, hippocampus, and periaqueductal gray lesions on short-and long-term contextual fear. Behav Neurosci. 1993; 107:1093. [PubMed: 8136063]

31. Rescorla RA, Wagner AR. A theory of Pavlovian conditioning: Variations in the effectiveness of reinforcement and nonreinforcement. Classical conditioning II: Current Research and Theory. 1972; 2:64-99.

32. Han S, et al. Elucidating an affective pain circuit that creates a threat memory. Cell. 2015; 162:363-374. [PubMed: 26186190]

33. Krout KE, et al. Periaqueductal gray matter projection to the parabrachial nucleus in rat. J Comp Neurol. 1998; 401:437-454. [PubMed: 9826272]

34. McCormick DA, et al. Lesions of the inferior olivary complex cause extinction of the classically conditioned eyeblink response. Brain Res. 1985; 359:120-130. [PubMed: 4075140] 
35. Watson JB, Rayner R. Conditioned emotional reactions. J Exp Psychol. 1920; 3:1.

36. Takahashi LK, et al. Predator odor fear conditioning: Current perspectives and new directions. Neurosci Biobehav Rev. 2008; 32:1218-1227. [PubMed: 18577397]

37. Wilensky AE, et al. Rethinking the fear circuit: The central nucleus of the amygdala is required for the acquisition, consolidation, and expression of Pavlovian fear conditioning. J Neurosci. 2006; 26:12387-12396. [PubMed: 17135400]

38. Ciocchi S, et al. Encoding of conditioned fear in central amygdala inhibitory circuits. Nature. 2010; 468:277-282. [PubMed: 21068837]

39. Haubensak W, et al. Genetic dissection of an amygdala microcircuit that gates conditioned fear. Nature. 2010; 468:270-276. [PubMed: 21068836]

40. Sotres-Bayon F, Quirk GJ. Prefrontal control of fear: More than just extinction. Curr Opin Neurobiol. 2010; 20:231-235. [PubMed: 20303254]

41. Apps R, Strata P. Neuronal circuits for fear and anxiety: The missing link. Nat Rev Neurosci. 2015; 16:642-642. [PubMed: 26333516]

42. Kida S, et al. CREB required for the stability of new and reactivated fear memories. Nat Neurosci. 2002; 5:348-355. [PubMed: 11889468]

43. Han JH, et al. Neuronal competition and selection during memory formation. Science. 2007; 316:457-460. [PubMed: 17446403]

44. Han JH, et al. Selective erasure of a fear memory. Science. 2009; 323:1492-1496. [PubMed: 19286560]

45. Josselyn SA, et al. Finding the engram. Nat Rev Neurosci. 2015; 16:521-534. [PubMed: 26289572]

46. Barot SK, et al. Functional imaging of stimulus convergence in amygdalar neurons during Pavlovian fear conditioning. PLoS One. 2009; 4:e6156-e6156. [PubMed: 19582153]

47. Fanselow, MS.; Lester, LS. A functional behavioristic approach to aversively motivated behavior: Predatory imminence as a determinant of the topography of defensive behavior. In: Bolles, RC.; Beecher, MD., editors. Evolution and Learning. Lawrence Erlbaum Associates, Inc; 1988. p. 185-212.

48. Ydenberg RC, Dill LM. The economics of fleeing from predators. Adv Study Behav. 1986; 16:229-249.

49. Boissy A. Fear and fearfulness in animals. Q Rev Biol. 1995:165-191. [PubMed: 7610234]

50. Sun H, Frost BJ. Computation of different optical variables of looming objects in pigeon nucleus rotundus neurons. Nat Neurosci. 1998; 1:296-303. [PubMed: 10195163]

51. Yilmaz M, Meister M. Rapid innate defensive responses of mice to looming visual stimuli. Current Biology. 2013; 23:2011-2015. [PubMed: 24120636]

52. Münch TA, et al. Approach sensitivity in the retina processed by a multifunctional neural circuit. Nat Neurosci. 2009; 12:1308-1316. [PubMed: 19734895]

53. Huberman AD, et al. Genetic identification of an on-off direction-selective retinal ganglion cell subtype reveals a layer-specific subcortical map of posterior motion. Neuron. 2009; 62:327-334. [PubMed: 19447089]

54. Wei P, et al. Processing of visually evoked innate fear by a non-canonical thalamic pathway. Nat Commun. 2015; 6

55. Choi JS, Kim JJ. Amygdala regulates risk of predation in rats foraging in a dynamic fear environment. Proc Natl Acad Sci. 2010; 107:21773-21777. [PubMed: 21115817]

56. Kim EJ, et al. Alterations of hippocampal place cells in foraging rats facing a "predatory" threat. Current Biology. 2015; 25:1362-1367. [PubMed: 25891402]

57. Amir A, et al. Amygdala signaling during foraging in a hazardous environment. J Neurosci. 2015; 35:12994-13005. [PubMed: 26400931]

58. Cianca V, et al. A robotics-based behavioral paradigm to measure anxiety-related responses in zebrafish. PLoS ONE. 2013; 8:e69661. [PubMed: 23922773]

59. Maren S, Quirk GJ. Neuronal signalling of fear memory. Nat Rev Neurosci. 2004; 5:844-852. [PubMed: 15496862]

60. Suraci JP, et al. Fear of large carnivores causes a trophic cascade. Nat Commun. 2016; 7 
61. Zanette LY, et al. Perceived predation risk reduces the number of offspring songbirds produce per year. Science. 2011; 334:1398-1401. [PubMed: 22158817]

62. Hartley T, et al. Space in the brain: How the hippocampal formation supports spatial cognition. Philos Trans R Soc Lond B Biol Sci. 2014; 369:20120510. [PubMed: 24366125]

63. Buzsáki G, Moser EI. Memory, navigation and theta rhythm in the hippocampal-entorhinal system. Nat Neurosci. 2013; 16:130-138. [PubMed: 23354386]

64. Kim JJ, Fanselow MS. Modality-specific retrograde-amnesia of fear. Science. 1992; 256:675-677. [PubMed: 1585183]

65. Phillips RG, LeDoux JE. Differential contribution of amygdala and hippocampus to cued and contextual fear conditioning. Behav Neurosci. 1992; 106:274-285. [PubMed: 1590953]

66. Moita MAP, et al. Hippocampal place cells acquire location-specific responses to the conditioned stimulus during auditory fear conditioning. Neuron. 2003; 37:485-497. [PubMed: 12575955]

67. Moita MAP, et al. Putting fear in its place: Remapping of hippocampal place cells during fear conditioning. J Neurosci. 2004; 24:7015-7023. [PubMed: 15295037]

68. Kim EJ, et al. Amygdalar stimulation produces alterations on firing properties of hippocampal place cells. J Neurosci. 2012; 32:11424-11434. [PubMed: 22895724]

69. Telensky P, et al. Functional inactivation of the rat hippocampus disrupts avoidance of a moving object. Proc Natl Acad Sci. 2011; 108:5414-5418. [PubMed: 21402943]

70. Mobbs D, et al. From threat to fear: the neural organization of defensive fear systems in humans. $\mathrm{J}$ Neurosci. 2009; 29:12236-12243. [PubMed: 19793982]

71. Mobbs D, et al. When fear is near: threat imminence elicits prefrontal-periaqueductal gray shifts in humans. Science. 2007; 317:1079-1083. [PubMed: 17717184]

72. Mobbs D, et al. Neural activity associated with monitoring the oscillating threat value of a tarantula. Proc Natl Acad Sci. 2010; 107:20582-20586. [PubMed: 21059963]

73. Mobbs D, Kim JJ. Neuroethological studies of fear, anxiety, and risky decision-making in rodents and humans. Curr Opin Behav Sci. 2015; 5:8-15.

74. Graziano MS, Cooke DF. Parieto-frontal interactions, personal space, and defensive behavior. Neuropsychologia. 2006; 44:845-859. [PubMed: 16277998]

75. Ferri F, et al. Emotion-inducing approaching sounds shape the boundaries of multisensory peripersonal space. Neuropsychologia. 2015; 70:468-475. [PubMed: 25744869]

76. Sambo CF, Iannetti GD. Better safe than sorry? The safety margin surrounding the body is increased by anxiety. J Neurosci. 2013; 33:14225-14230. [PubMed: 23986256]

77. Fenn MG, Macdonald DW. Use of middens by red foxes: Risk reverses rhythms of rats. J Mammal. 1995; 76:130-136.

78. Amir S, Stewart J. Conditioned fear suppresses light-induced resetting of the circadian clock. Neuroscience. 1998; 86:345-351. [PubMed: 9881852]

79. Wulff K, et al. Sleep and circadian rhythm disruption in psychiatric and neurodegenerative disease. Nat Rev Neurosci. 2010; 11:589-599. [PubMed: 20631712]

80. Pellman BA, et al. Time-specific fear acts as a non-photic entraining stimulus of circadian rhythms in rats. Sci Rep. 2015; 5

81. Landgraf $\mathrm{R}$, et al. Candidate genes of anxiety-related behavior in $\mathrm{HAB} / \mathrm{LAB}$ rats and mice: Focus on vasopressin and glyoxalase-I. Neurosci Biobehav Rev. 2007; 31:89-102. [PubMed: 16934871]

82. Overstreet DH, et al. The Flinders Sensitive Line rat: A selectively bred putative animal model of depression. Neurosci Biobehav Rev. 2005; 29:739-759. [PubMed: 15925699]

83. Hall CS. Emotional behavior in the rat. III. The relationship between emotionality and ambulatory activity. J Comp Psychol. 1936; 22:345-352.

84. Bush DEA, et al. Individual differences in fear: Isolating fear reactivity and fear recovery phenotypes. J Trauma Stress. 2007; 20:413-422. [PubMed: 17721971]

85. Hartley CA, et al. Brain structure correlates of individual differences in the acquisition and inhibition of conditioned fear. Cerebral Cortex. 2011; 21:1954-1962. [PubMed: 21263037]

86. Galatzer-Levy IR, et al. Heterogeneity in threat extinction learning: substantive and methodological considerations for identifying individual difference in response to stress. Front Behav Neurosci. 2013; 7:55. [PubMed: 23754992] 
87. Feinstein JS, et al. Fear and panic in humans with bilateral amygdala damage. Nat Neurosci. 2013; 16:270-272. [PubMed: 23377128]

88. Carrive P, Morgan MM. Periaqueductal gray. The Human Nervous System. 2004:393-423.

89. Kunwar PS, et al. Ventromedial hypothalamic neurons control a defensive emotion state. Elife. 2015; 4:e06633.

90. Bolles RC. Species-specific defense reactions and avoidance learning. Psychol Rev. 1970; 77:3248.

91. Papes F, et al. The vomeronasal organ mediates interspecies defensive behaviors through detection of protein pheromone homologs. Cell. 2010; 141:692-703. [PubMed: 20478258]

92. Ferrero DM, et al. Detection and avoidance of a carnivore odor by prey. Proc Natl Acad Sci. 2011; 108:11235-11240. [PubMed: 21690383]

93. Rosen JB, et al. The smell of fear: Innate threat of 2, 5-dihydro-2, 4, 5-trimethylthiazoline, a single molecule component of a predator odor. Front Neurosci. 2015; 9:292. [PubMed: 26379483]

94. Yang H, et al. Laterodorsal tegmentum interneuron subtypes oppositely regulate olfactory cueinduced innate fear. Nat Neurosci. 2016; 19:283-289. [PubMed: 26727549] 


\section{Trends Box}

The expression of fear is shaped by an organism's evolutionary history and ecology, and fear has pervasive effects on neural systems and behavior, altering cost-benefit decision making, spatial navigation, and even biological clocks, among others.

While the amygdala seems necessary for many forms of defensive behavior, emerging evidence suggests fear networks that include the hypothalamus, PAG, and mPFC, among others, are distributed throughout the brain and some may support fear responses without the amygdala.

Fear and reward-based decision making are not mutually-exclusive systems, and ethological experiments can examine how they interact to produce behavioral decisions that balance perceived costs and benefits. 
(a)

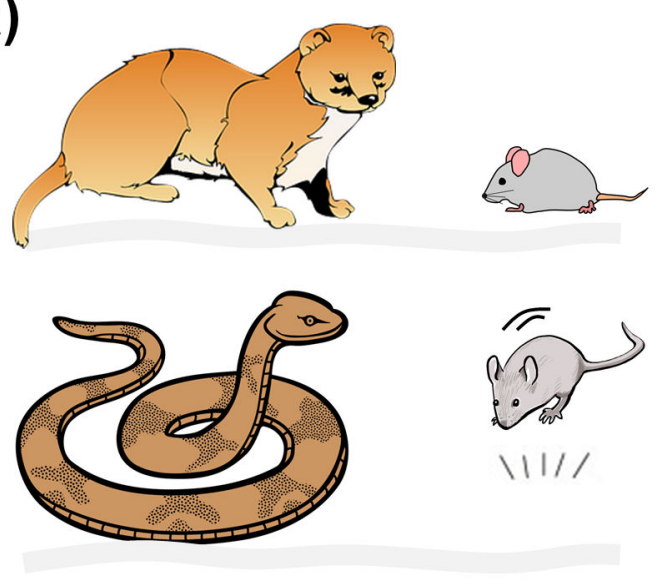

(b)

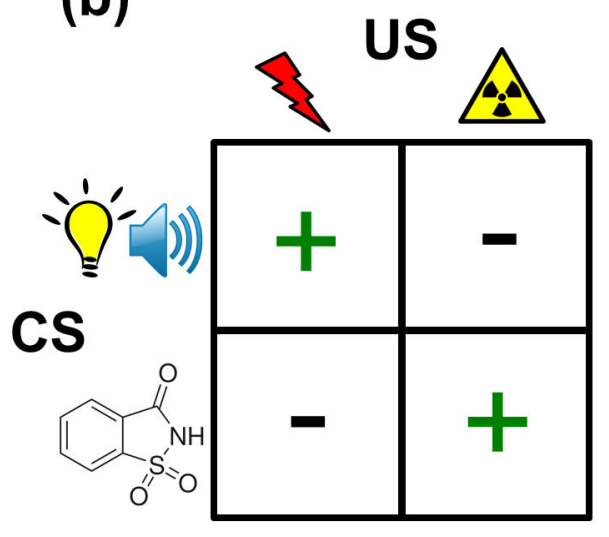

Figure 1. Evolutionary influences on innate and learned fear

(A) Predatory history shapes prey's innate fear responses as illustrated by $m$. austerus deermouse's freezing to weasel and $P$. m. gambeli deermouse's jump (Jan Gillbank, "Drawing of a grey mouse" October 27, 2012 via Wikimedia, Creative Commons Attribution 3.0 License) to gopher snake [2]. P.m. austerus deermice live in the coniferous forests of western Washington State and P.m. gambeli deermice dwell in the arid grassland of eastern Washington State. (B) Ecological history predisposes fear learning. A classic study by John Garcia [3] found that rats easily acquired conditioned fear to bright/noisy CS paired to footshock US and conditioned taste aversion to saccharin taste CS paired to X-rays (or $\mathrm{LiCl}$ ) US. However, rats showed lack of conditioning to bright/noisy-X-ray (or LiCl) and saccharin-footshock pairings. 


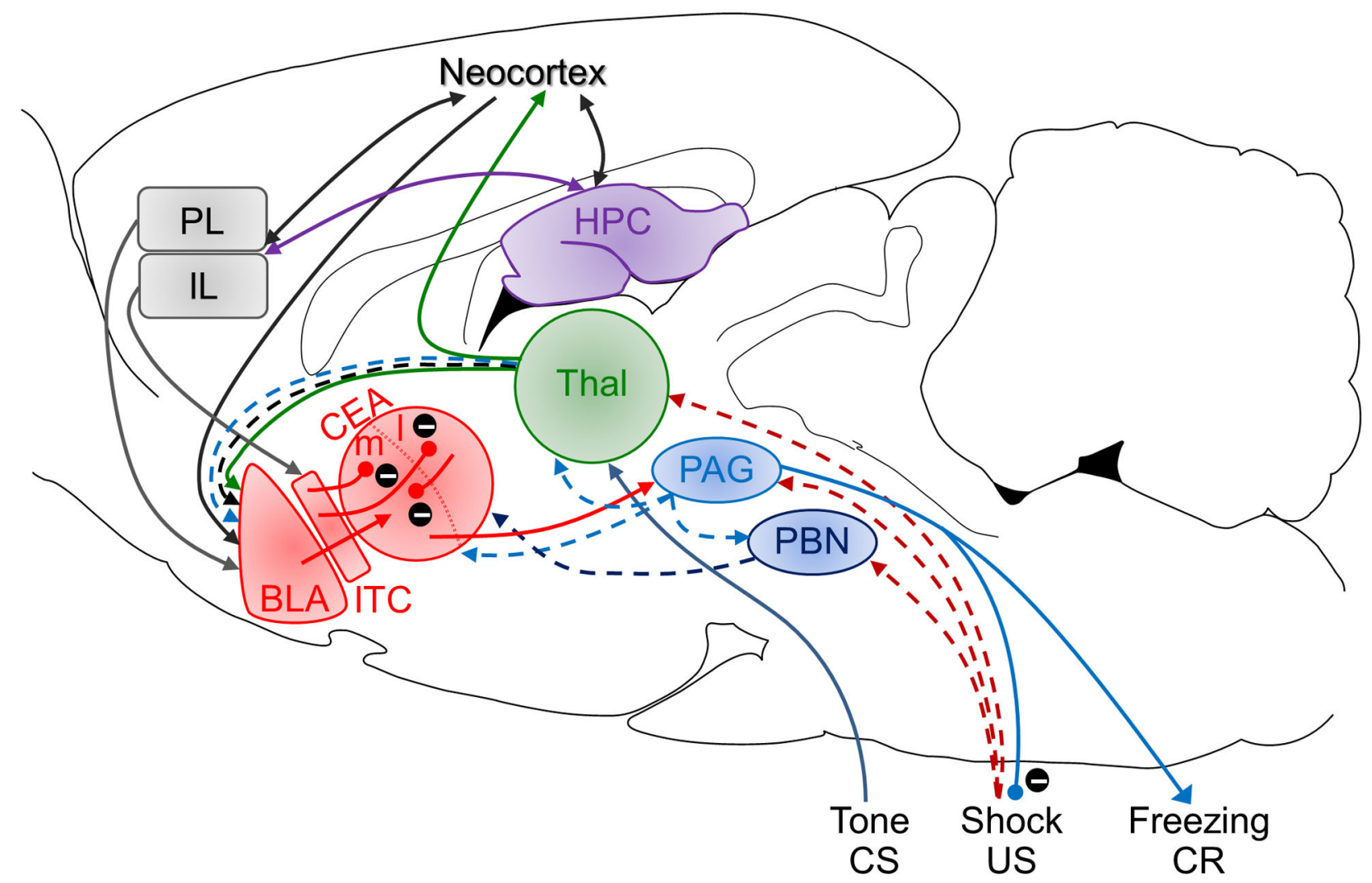

Figure 2. A putative fear conditioning circuit

The auditory CS information reaches the amygdala via the direct thalamic pathway and indirect cortical pathway. The footshock US information is relayed to the amygdala via the ascending pain pathways. The CS-US association formation is thought to occur in specific subnuclei via associative LTP-like mechanism that strengthens the CS-amygdala synapses. BLA, basolateral complex of the amygdala; CEA, central nucleus of the amygdala; ITC, intercalated cells of the amygdala; PL, prelimbic cortex; IL, infralimbic cortex; HTP, hippocampus; Thal, thalamus; PAG, periaqueductal gray; PBN, parabrachial nucleus. Inhibitory pathways are represented by encircled minus symbols. 


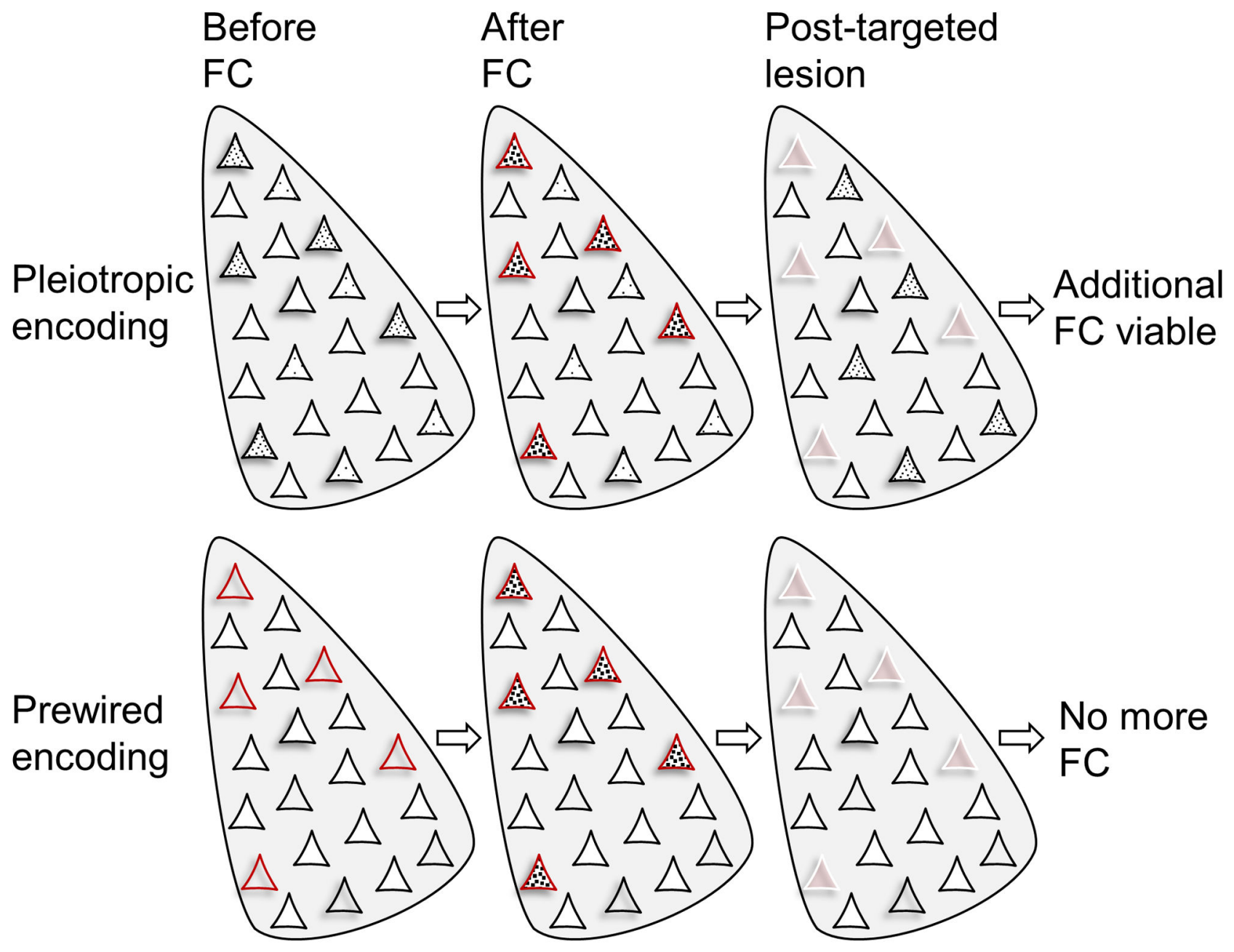

Figure 3. Two fear memory encoding schemas

(Top) Amygdalar neurons with relatively higher CREB activity (denoted by black dots) form a memory trace (an engram) following fear conditioning (fear conditioning). When those neurons are ablated (represented by white borders), the fear memory is abolished. However, those remaining neurons with higher CREB activity can then support new fear memory formation. (Bottom) Small subset of amygdalar neurons that receive both CS and US information are biologically predetermined, irrespective of relative basal CREB level, to support fear memory. When those neurons are eliminated, fear memory cannot be formed regardless of increasing CREB activity in remaining neurons. 


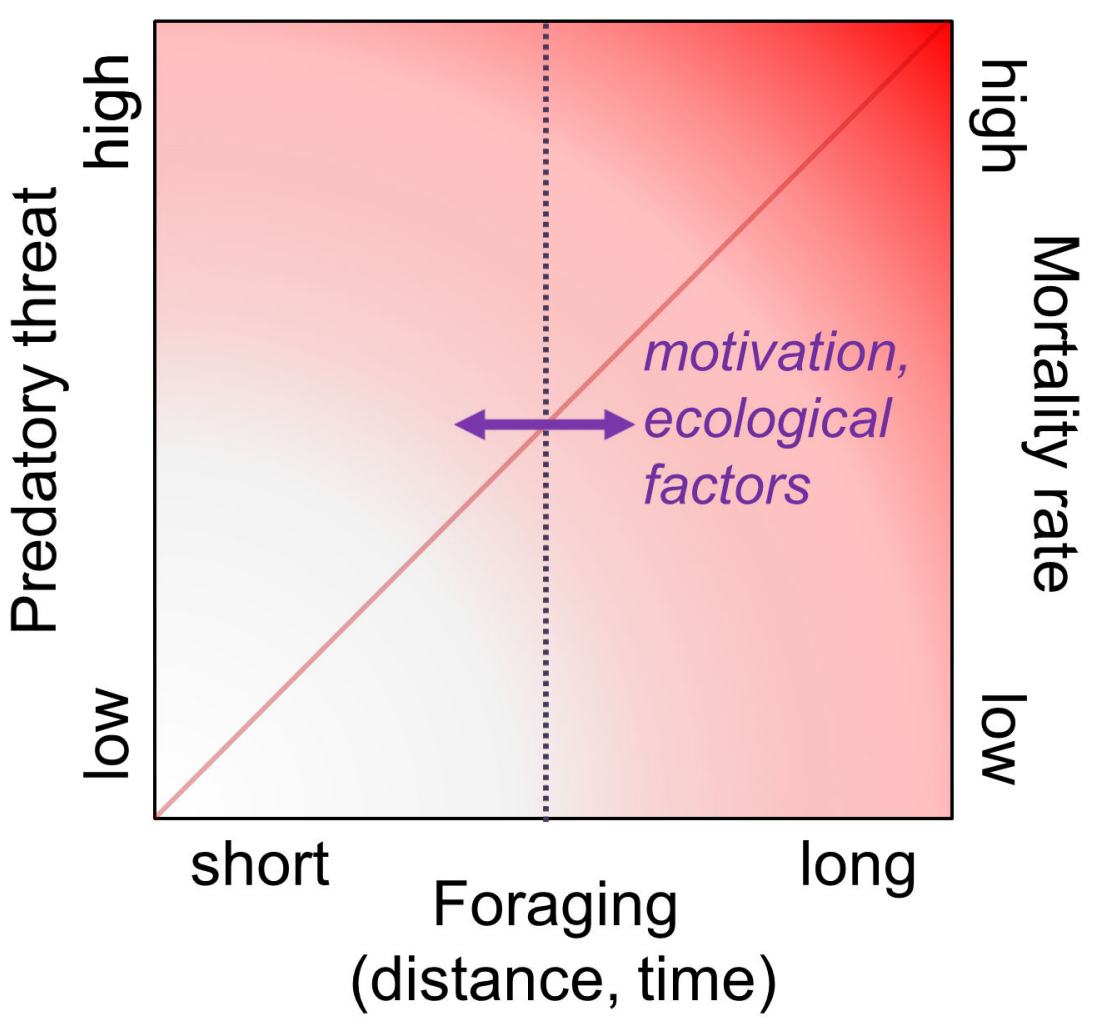

Figure 4. Foraging and risk of predation

Foraging distance and time away from the safety of a nest are positively correlated with the risk of meeting predators which can result in injury or death. Motivational factors, such as hunger, reproductive and parental state, and ecological factors, such as food availability and predator density, influence foraging behavior (represented by a horizontal arrow) and thus predation risk. Fear elicits immediate species-specific defense reactions upon meeting a predator and exerts enduring influences on foraging strategy. 
(a)
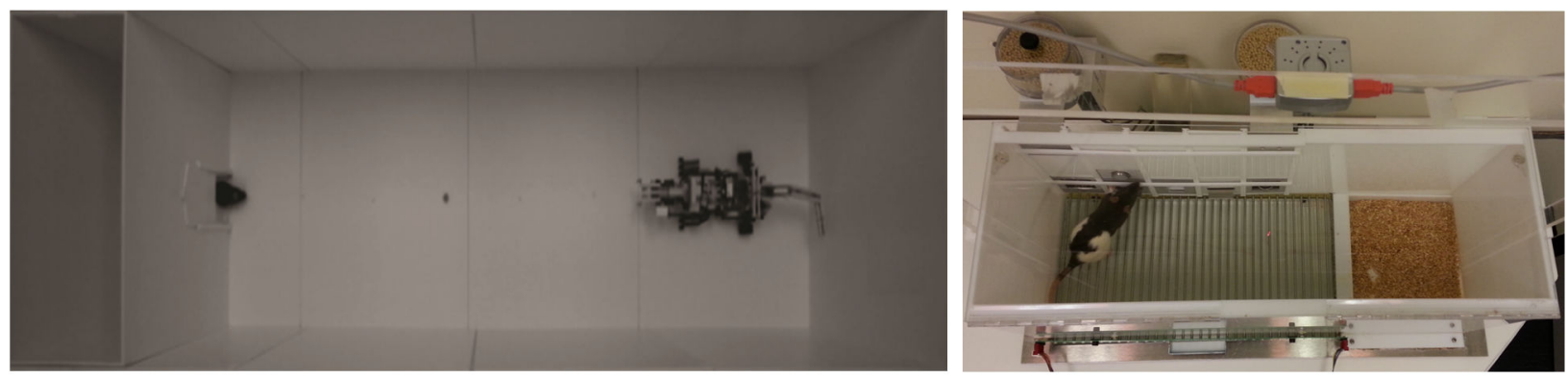

(b)

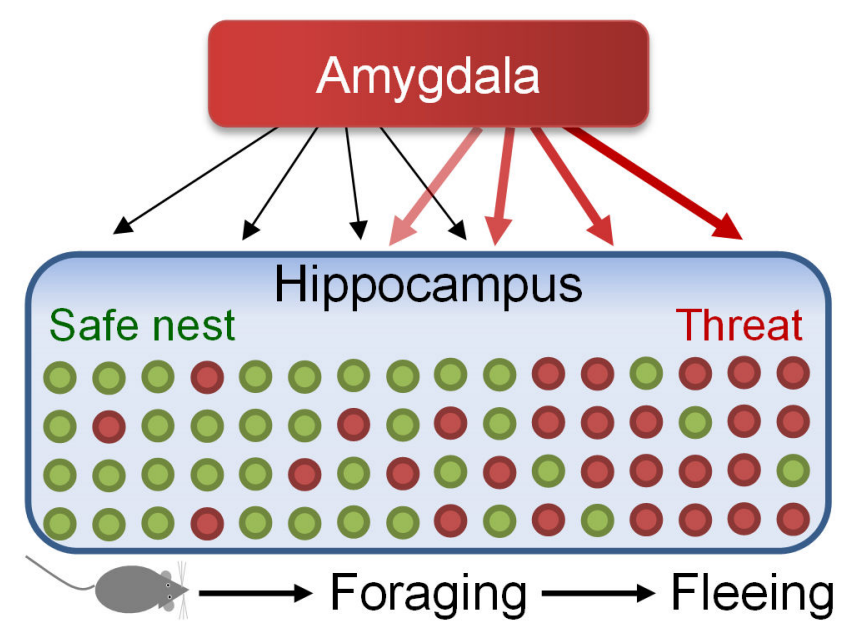

(c)

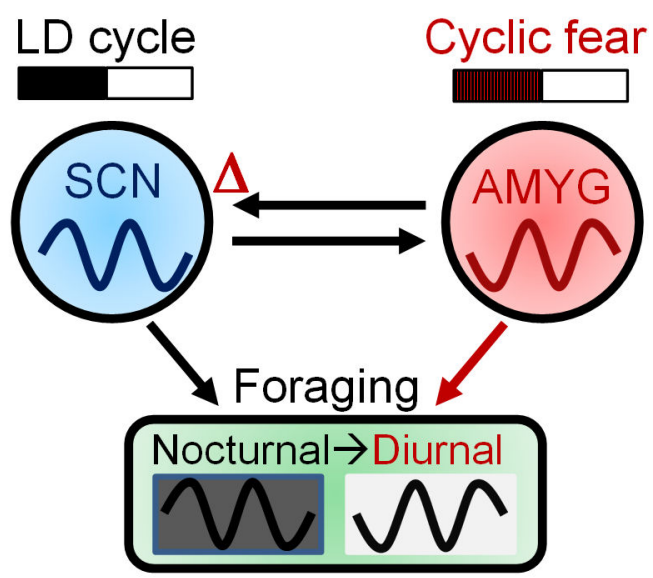

Figure 5. Fear influences foraging distance and time

(A) Ecologically-relevant 'approach food-avoid predator' (left) and ‘closed economy' (right) paradigms. (B) In the approach-avoid paradigm, a hunger-motivated rat seeks food pellets placed at varying distances from the nest. As the animal nears the food, the predatory robot executes a programmed set of threatening actions, i.e., surges forward a fixed distance and snaps its 'jaws' before returning to its starting position. In response, rats instinctively flee into the safety of the nest and freeze inside. This is followed by the rat's display of a stretched posture anchored inside the nest opening as it scans the outside area (riskassessment), and then cautiously venturing out, pausing, and moving toward the food until the robot's surge retriggers the rat's fear responses. While all rats were unable to procure the pellet placed distal to the nest, most were able to acquire the pellet placed near the nest, suggesting that rats form a distance gradient of fear near the robot [55]. In parallel, hippocampal place cells exhibited remapping of place fields and increased theta rhythm as the animals advanced toward the vicinity of the robot but not inside/near the nest regions [56]. These behavioral and neurophysiological effects were abolished by amygdalar lesions/ inactivation. (C) In the closed economy paradigm, fear, avoidance, and appetitive behaviors are integrated within the rat's living situation. It consists of a safe nest and foraging zone that has to be entered to press levers for food and can be rendered dangerous by footshocks. When footshocks were pseudo-randomly presented only during the dark phase of the 12 $\mathrm{h} / 12 \mathrm{~h}$ light:dark (LD) cycle, rats switched their natural foraging behavior from the dark to the light phase, and this switch was maintained as a free-running circadian rhythm upon 
removal of light cues and footshocks. This fear-entrained circadian behavior was dependent on an intact amygdala (AMYG) and suprachiasmatic nucleus (SCN) [80]. 


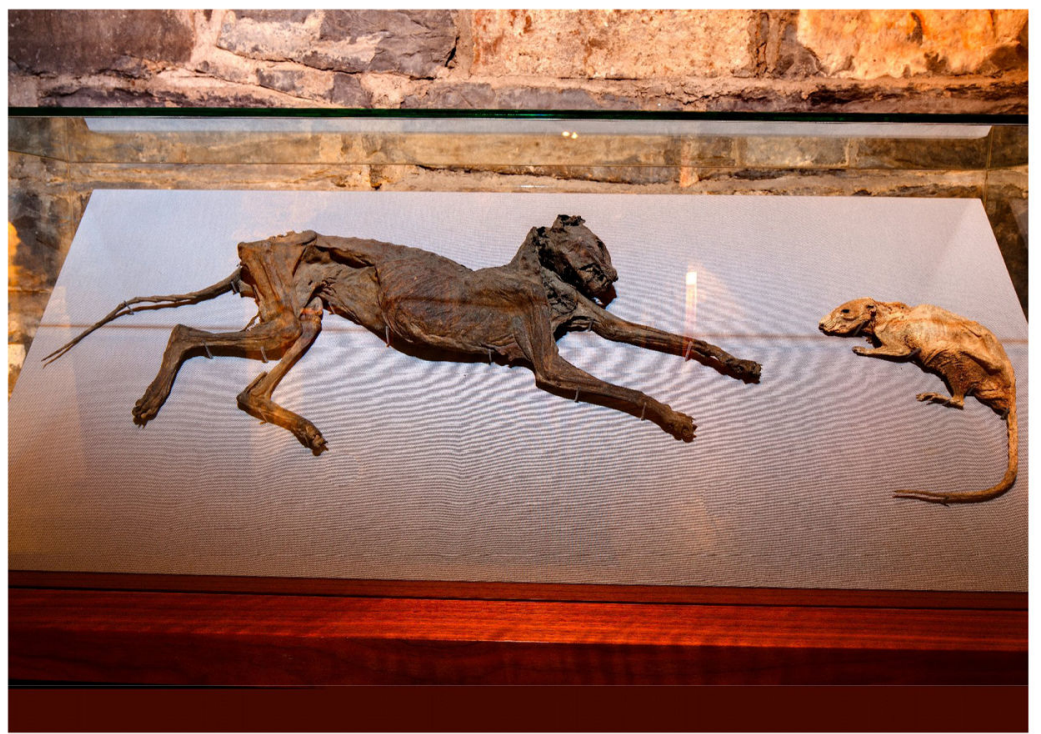

Caption 1.

"The Cat and the Rat" of the Christ Church Cathedral in Dublin, Ireland (founded c. 1028). The cat presumably in chase and the rat in flight were trapped in an organ pipe in the 1850s and became mummified. Alluded to by James Joyce in "Finnegans Wake". The photograph courtesy of Christ Church Cathedral, Dublin, Ireland. 